\title{
Metallography - A Powerful Instrument for Material Characterisation, Material Development and Failure Analysis
}

\author{
Michael Panzenböck ${ }^{1}$, Francisca Mendez-Martin ${ }^{1}$, Boryana Rashkova ${ }^{1}$, Patric Schütz ${ }^{1}$ \\ 1. Department of Physical Metallurgy and Materials Testing, Montanuniversität Leoben, Austria
}

A. Widmanstätten (1754-1849) was one of the first scientists who developed techniques for studying the microstructure of meteorites by grinding and etching them with nitric acid. Also H.C. Sorby (18261908) used such methods for microstructural investigations of minerals and rocks to identify their origin, as well as to examine steels and meteorites. Other famous and nowadays well known researchers such as R. Hadfield (1858-1940), A. Martens (1850-1914), E.C. Bains (1891-1971), K.H. Ledebur (18371906), and H. Brearley (1871-1948) further developed these basic methods to get more information about the microstructure, especially in case of steels. Many microstructural parts or phases of the Fe$\mathrm{Fe}_{3} \mathrm{C}$ phase diagram are called in honour of these scientists, e.g., "Widmanstätten ferrite", "Sorbite", "Bainite", "Martensite", or in case of cast iron "Ledeburite".

Without doubt, a material's microstructure is decisive, because it is the arrangement, size and distribution of different phases which is responsible for the mechanical properties such as strength, ductility and toughness. In order to develop high-performance materials for existing and new applications it is necessary to establish a basic understanding of the material behaviour or its response under service loads. In addition to the standard methods such as light microscopy (LM), scanning electron microscopy (SEM), focused ion beam (FIB), also high-resolution methods (transmission electron microscopy (TEM), atom probe tomography (APT)) have been developed over the last three decades. Moreover, advanced test equipment is used, to identify material behaviour in various conditions and environments. We want to present the role of metallography in the fields of material development [1] and failure analyses [2], as described here for one example.

Figure 1 shows an overview of broken supports. Macroscopic investigations reveal dark spots within the crack surface. This indicates that such defects were responsible for the failure of many supports. Further investigations revealed [2] that the area of crack initiation was covered with $\mathrm{Zn}$, which originates from hot dip galvanization. A cut through such broken and unbroken parts in longitudinal direction revealed cracks covered with $\mathrm{Zn}$ (Fig. 2). The light-optical micrograph shows the Zn-layer followed by the microstructure of the steel, which consists of ferrite and a small amount of pearlite, as can be seen far away from the Zn-layer. However, it seems that regions near the Zn-layer exhibit a nearly pure ferrite structure. This can be attributed to an effect of decarburisation. The "ferritic" microstructure is caused by the cathodic protection due to zinc during etching with Nital-solution. In this case the cracks can be attributed to a liquid metal embrittlement (LME).

Between the years 2000 and 2010 many failures of steel constructions occurred due to LME. In many cases, polluted Zn, used for the hot dip galvanization process, was identified [3] as a trigger for LME. Elements such as $\mathrm{Pb}, \mathrm{Sn}$, and $\mathrm{Sb}$ were typically identified with high concentration of more $1 \mathrm{wt} \%$. In this case, a content of less than $0.1 \mathrm{wt} \%$ was found. In contrast to the $\mathrm{Zn}$ layer, high concentrations of $\mathrm{Cu}$ (about $0.45 \mathrm{wt} \%$ ), Sn $(0.12 \mathrm{wt} \%$ ) and $\mathrm{Sb}$ (about $0.1 \mathrm{wt} \%$ ) were found in the steel used for the supports. It is not possible to detect local enrichments of these elements with standard metallographic methods. Therefore, we used APT to prove the enrichment of $\mathrm{Cu}$ and $\mathrm{Sn}$ on or near grain boundaries. The results 
are shown in Fig. 3. The preparation of the tip (Figs. 3a, b) was made by using etching methods and subsequent milling by FIB. The process was controlled by electron back-scatter channelling diffraction (EBSD) to ensure that a grain boundary is in the investigated region. The grain boundaries are covered with precipitates of $\mathrm{Cu}$ and $\mathrm{Sn}$ (Figs. 3c, d). Additionally, ternary cementite is visible.

\section{References}

[1] S. Mayer, G. Hawranek, F. Mendec-Martin, M. Panzenböck, S. Pölzl, S. Primig, B. Rashkova, H. Clemens, to be published in Practical Metallography (2015)

[2] M. Panzenböck, P. Schütz, Microscopy and Microanalyses, 20 (2014), p. 1868

[3] A. Durst, A. Luithle, W. Bleck, M. Pohl, Practical Metallography, 48 (2011), p. 6.

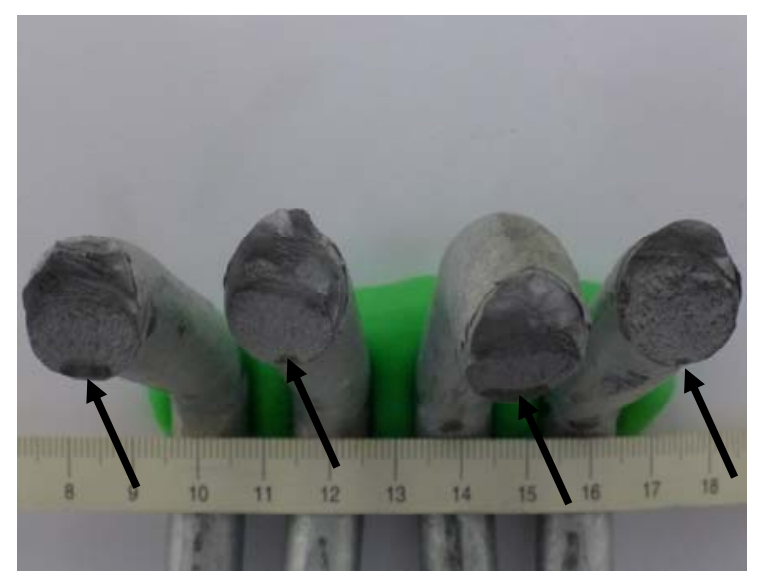

Figure 1. Macroscopic overview of the fracture surface. Arrows mark the region of crack initiation (dark spots).

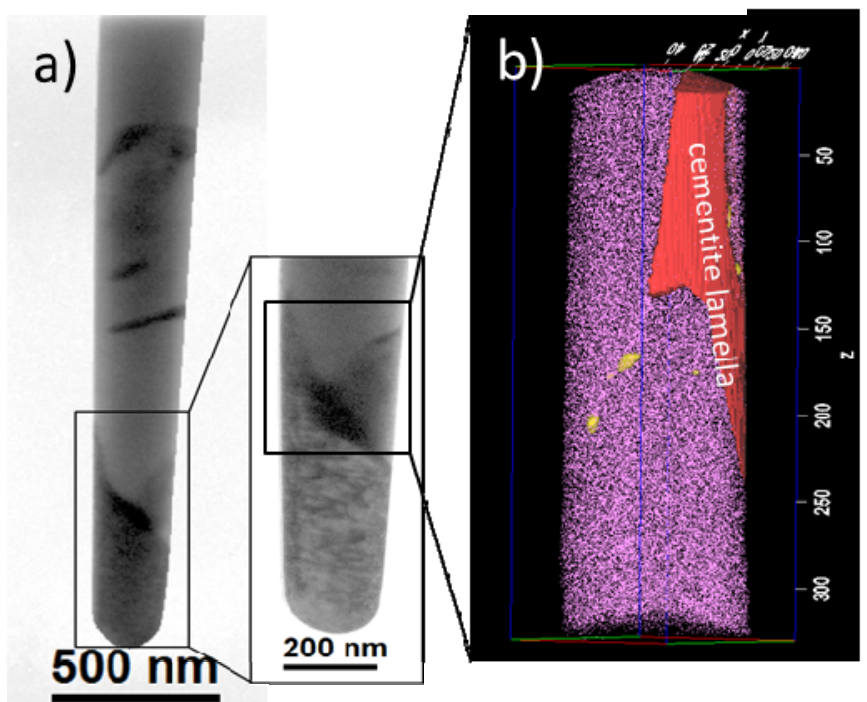

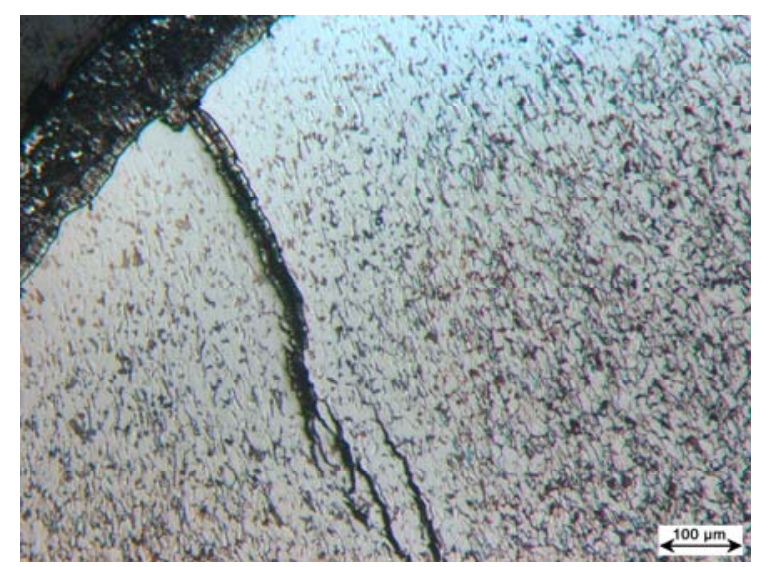

Figure 2. Light-optical micrograph of a crack after etching with Nital. The crack surface is covered with zinc.

Figure 3. TEM images (a) of an atom probe tomography (APT) specimen (prepared by FIB) of a broken support. The results reveal fine $\mathrm{Cu}$ - and $\mathrm{Sn}$-rich precipitates at the grain boundaries between a cementite lamella and the iron $\alpha$-matrix. Fe atoms are shown in pink (b), $\mathrm{Cu}$ isosurfaces in yellow and $\mathrm{Sn}$ isosurfaces in green. The grain boundary between the cementite lamella and the iron $\alpha$-matrix is indicated in red color in (c) and (d). 